\title{
MÚSICA NA ESCOLA E FORMAÇÃO DOCENTE: OS PROFESSORES ESTÃO PREPARADOS?
}

\author{
Tatiane Mota Santos Jardim, Fábio Luiz da Silva \\ Universidade Norte do Paraná - UNOPAR. Londrina - PR. E-mail: tati.jardim@hotmail.com
}

\begin{abstract}
RESUMO
Este artigo é um recorte da minha dissertação de mestrado em andamento sobre as práticas, os saberes e sobre o ensino de música nas escolas urbanas da Rede Municipal de Londrina-Pr. O referencial teórico está fundamentado em Tardif (2000/2002), complementado por reflexões da área da educação musical. Trata-se de uma pesquisa com abordagem mista quantitativa e qualitativa. Os dados coletados indicam que $79 \%$ dos professores atuantes em escolas urbanas da Rede Municipal de Londrina que participaram da pesquisa e trabalham com a música na escola são pedagogos e relataram não ter recebido formação paralela e/ou posterior ao período de graduação no que se refere ao conteúdo musical. Este estudo pretende discutir sobre a lei $n^{\circ}$ 11.769/08 que institui a música como conteúdo em toda a educação básica e os novos encaminhamentos perante a lei, principalmente no que se refere à programas de formação docente inicial e continuada.
\end{abstract}

Palavras-chave: Música. Escola. Lei. Saberes. Formação Docente.

\section{MUSIC AT SCHOOL AND TEACHER EDUCATION: ARE TEACHERS PREPARED?}

\begin{abstract}
This article is an excerpt from my dissertation in progress on the practices, knowledge, and on teaching music in urban schools Municipal de Londrina-Pr. The theoretical framework is based on Tardif (2000/2002), complemented by reflections in the field of music education. This is a survey of quantitative and qualitative mixed approach. The data are in pre-analysis process and indicate that $79 \%$ of the teachers that work in urban municipals schools in Londrina which participated in the survey and work with music in the school are pedagogues and reported have not received parallel and / or further training after the graduation period with respect to the musical content. This study aims to discuss the law at 11,769 / 08 establishing music as content in all basic education and new referrals before the law, especially with regard to the initial and continuing teacher education programs.
\end{abstract}

Keywords: Music. School. Law. Knowledge. Teacher Training. 


\section{INTRODUÇÃO}

No dia 18 de agosto de 2008, foi promulgada a lei $n^{0} 11.769 / 08$ que dispõe sobre a obrigatoriedade do ensino de música na educação básica. Foi vetado porém o artigo que especificava que o conteúdo deveria ser ministrado por professores específicos da área, alegando que no Brasil existem diversos profissionais atuantes, sem formação acadêmica ou oficial.

Esse veto traz à tona a discussão sobre o ensino de música na escola, os profissionais que irão trabalhar com tal conteúdo, a formação docente inicial e continuada dos professores e os novos encaminhamentos à partir da referida lei.

Diante destas questões buscou-se pesquisar o ensino de música nas escolas urbanas da Rede Municipal de Ensino de Londrina-PR. A cidade está localizada no norte do Paraná e segundo dados do site da Secretaria Municipal de Educação, em 2014, foram matriculados 27.926 alunos nas séries iniciais do ensino fundamental.

O município não apresenta concurso específico para professores de música, mas oferece oficinas em escolas com ampliação de jornada, aulas de músicas através de projetos específicos e ainda desenvolve projetos em parceria com a Secretaria de Cultura.

Diante desses projetos surgem os questionamentos sobre a formação dos profissionais que trabalham com a música na escola, já que embora existam alguns profissionais licenciados em música, a grande maioria deles são pedagogos.

Ao pesquisar as práticas e o ensino de música, bem como a formação docente e os saberes dos professores das escolas urbanas da Rede Municipal de Ensino de Londrina-PR, espera-se possibilitar a reflexão de estratégias para os novos encaminhamentos a partir da lei $n^{\circ} 11.769$ contribuindo com o desenvolvimento da educação musical no município.

\section{Música na escola e formação docente}

A escola é um ambiente propício para o desenvolvimento e a troca de experiências. A diversidade musical encontrada na escola torna-se rica por ser fruto das vivências dos alunos, seja pela prática propriamente dita, seja pelas descobertas através da mídia, religião, hábitos familiares, amigos ou preferências musicais.

Concebendo a escola como lugar privilegiado na mediação da cultura e a música como um veículo universal de expressão das culturas, o diálogo entre esse lugar de formação cultural, a escola, e esse importante saber humano, a música, se estabelece de forma natural (QUEIROZ, 2013, p. 100). 
Várias cidades brasileiras tem desenvolvido projetos e aulas de música em suas escolas e muitos deles antes mesmo da promulgação da lei $n^{0} 11.769 / 08$. Podemos citar as pesquisas de Veber (2009), Puerari (2011) e Gaulke (2013) para apresentar o destaque que o tema tem recebido no meio acadêmico.

Mas como conseguir tal êxito se o professor não tiver vivência com música? Qual a formação recebida pelos profissionais que estão na escola? Quais os saberes docentes necessários para desenvolver a música nesse ambiente?

Torna-se necessário a atenção com o profissional que irá atuar na escola para que a música não se torne apenas uma prática mecânica ou irrelevante na formação dos alunos ou ainda apenas uma experiência vaga relacionada a apreciação musical de gêneros ou estilos da preferência do professor. Para se ensinar música é necessário ter vivência em música, ouvir, tocar, cantar, interagir e relacionar-se com ela, para que assim os alunos consigam descobrir as diferentes possibilidades de interação musical.

\section{Saberes docentes}

Tardif (2012) define o saber docente como "um saber plural, formado pelo amálgama, mais ou menos coerente, de saberes oriundos da formação profissional e de saberes disciplinares, curriculares e experienciais" (TARDIFF, 2012, p. 36).

Os saberes profissionais são o conjunto de saberes transmitidos pelas instituições formadoras, produzidos pelas ciências da educação e dos saberes pedagógicos que,

...apresentam-se como doutrinas ou concepções provenientes de reflexões sobre a prática educativa no sentido amplo do termo, reflexões racionais e normativas que conduzem a sistemas mais ou menos coerentes de representação e de orientação da atividade educativa (TARDIF, 2012, p. 37).

Pode-se chamar de saberes disciplinares os saberes sociais, oriundos de diferentes campos do conhecimento, que emergem da tradição cultural e dos grupos sociais e são transmitidos através das disciplinas em cursos e departamentos universitários.

Os saberes curriculares correspondem aos "discursos, objetivos, conteúdos e métodos a partir dos quais a instituição escolar categoriza e apresenta os saberes sociais por ela definidos e selecionados como modelo da cultura erudita e de formação para a cultura erudita" (TARDIF, 2012, p. 38).

Já os saberes desenvolvidos no seu cotidiano, na experiência da prática docente, são chamados de experienciais. Podemos observar que "os saberes são elementos constitutivos da 
prática docente (TARDIF, 2012, p. 39). O autor afirma ainda que "chamamos tradicionalmente de saberes os discursos que afirmam algo de verdadeiro a respeito da natureza da realidade ou de tal fenômeno particular" (2012, p. 195).

O saber dos professores está atrelado às especificidades de uma determinada área, assunto ou conteúdo, influenciado pelos sujeitos, suas vivências e suas ações, além do próprio ambiente de trabalho.

\section{Saberes docentes na educação musical}

A pesquisa sobre formação docente na educação têm influenciado estudos e pesquisas sobre a formação de professores de música e seus saberes docentes. Pesquisas como as de Bellochio (2003) e Araújo (2005) destacam a necessidade de dar mais atenção ao assunto.

É necessário dar maior atenção para a formação não só do professor de música, como também para a formação musical na graduação em pedagogia. Furquim; Bellochio (2010) relatam sobre a necessidade de formação desse profissional que tem acesso direto com os alunos das séries iniciais.

Não se trata de capacitar o pedagogo e excluir o licenciado em música, pelo contrário, afirmamos a necessidade do profissional licenciado em música ganhar o seu espaço na escola e desenvolver de fato um trabalho de educação musical, mas esse processo pode sim acontecer em parceria entre os dois profissionais.

A reflexão sobre os saberes docentes mobilizados pelos professores na educação como um todo e especificamente na educação musical possibilitam entre outras ações, o desenvolvimento e a qualidade da educação e a valorização da profissão docente.

\section{METODOLOGIA}

Do ponto de vista metodológico optou-se por uma pesquisa com abordagem mista quantitativa e qualitativa, através de um estudo de campo, tendo como sujeitos da pesquisa os professores que atuam nas escolas municipais de Londrina-Pr.

...a pesquisa de campo é aquela utilizada com o objetivo de conseguir informações e/ou conhecimentos acerca de um problema para o qual se procura uma resposta, ou de uma hipótese que se queira comprovar, ou, ainda, descobrir novos fenômenos ou as relações entre eles (GIL, 1996, p. 69).

Na primeira fase da pesquisa os professores responderam um questionário aberto com questões relacionadas à formação pessoal, práticas musicais realizadas ou não nas escolas 
municipais e saberes docentes e na segunda fase da pesquisa foram realizadas seis entrevistas semi-estruturadas com coordenadores dos projetos "Um canto em cada canto" e "Musicando na escola", ambos em parcerias com a Secretaria de Cultura, uma entrevista com duas funcionárias da secretaria de educação do município e uma entrevista com um supervisor de estágio da Universidade Estadual de Londrina. Essas entrevistas possibilitaram a compreensão dos projetos, bem como os objetivos, dificuldades, avanços e formações existentes no Município.

A pesquisa contou ainda com uma terceira fase composta de observações de aulas de música ministradas por três professoras concursadas pelo município que se formaram em 2013 no curso de Segunda Licenciatura em Música, vinculado à Política Nacional de Formação dos Professores do Magistério da Educação Básica - PARFOR, proposto pelo MEC em regime de colaboração com a Universidade Estadual de Londrina (UEL), seguida de uma entrevista com cada profissional.

\section{RESULTADOS}

Das 73 escolas municipais presentes na zona urbana de Londrina-Pr, 67 escolas aceitaram participaram da pesquisa, contudo, somente 46 escolas tiveram retorno dos questionários. Destas, 15 estão localizadas na região norte, 10 na região sul, 8 na região leste, 9 na região oeste e 4 escolas na região central.

Foram respondidos 305 questionários, sendo 38 da região oeste, 76 da região sul, 58 da região leste, 112 da região norte e 21 da região central. Ateremos-nos neste artigo a apresentar as respostas obtidas nas questões número 1, 4 e 5 relacionadas à formação acadêmica, formação musical anterior ao ingresso na graduação e formação musical paralela e/ou posterior à graduação.

Quando questionados sobre sua formação, dos 305 professores que responderam aos questionários, 154 eram pedagogos, 5 são licenciados em música, 1 professora é formada em artes e música, 1 professor é formado em educação artística e os demais são licenciados em outras áreas do conhecimento.

No que se refere à vivência ou formação musical anterior à graduação, 57 professores disseram ter experiências musicais nas áreas de piano, teclado, violão, bateria e técnica vocal/canto e 248 professores garantiram não ter formação em música anterior ao período de graduação. 
Quando questionados sobre a formação paralela e/ou posterior à graduação, 242 professores relataram não ter recebido orientação sobre como trabalhar com o conteúdo musical e 63 disseram ter participado de palestras, cursos e oficinas relacionadas à música na escola.

Em entrevista com duas funcionárias da Secretaria de Educação que fazem parte da equipe de apoio pedagógico de arte e são responsáveis por ministrar cursos de formação continuada para os professores da rede municipal, verificamos que o município tem oferecido cursos relacionados ao conteúdo musical, porém nem todos os professores participam dessas formações.

\section{DISCUSSÃO}

Os dados indicam que $81 \%$ dos professores que atuam na escola disseram não ter vivência musical anterior à graduação e 79\% disseram não ter recebido formação paralela e/ou posterior ao período de graduação no que se refere ao conteúdo musical. Sendo assim, como esses professores irão trabalhar com a música na escola?

Dos 63 professores que disseram ter recebido orientações paralela e/ou posterior à graduação, apenas 22 disseram ter recebido orientações nas disciplinas ministradas na graduação e 6 professores na pós-graduação. Através desses dados podemos verificar a necessidade de orientações mais específicas sobre a música na escola também para os cursos de pedagogia.

Podemos observar que embora as funcionárias da Secretaria Municipal de Educação tenham garantido que o município ofereça cursos sobre a música na escola, nem todos os professores participam dessas formações.

A oferta desses cursos é evidenciada também no comentário do professor P36 "Sim. A prefeitura quando promove cursos de atualizações, quase sempre, coloca a disposição de educadores a opção do trabalho com musicalização".

Então porque muitos professores não participam dos cursos?

$\mathrm{Na}$ análise dos questionários é possível verificar que muitos deles não trabalham com a música por relatarem não possuírem formação na área. Nota-se que eles se referem à formação inicial e formação realizada no período de graduação. Essa análise mais uma vez evidencia a necessidade do diálogo entre educadores musicais e professores das séries iniciais citados anteriormente.

Ainda com relação à formação dos professores houve a predominância nas entrevistas das professoras licenciadas pelo PARFOR sobre a importância da formação aliando teoria e prática, ou seja, apresentando qual a fundamentação de determinadas atividades, quais seus objetivos e metodologias. 
Quando questionadas sobre quais conhecimentos elas consideravam ter adquirido no curso de Segunda Licenciatura em Música uma das professoras declarou: "Foi essa questão de conhecer o que cada educador musical pensava sobre como ensinar música. Coisas que eu fazia, mas não sabia de onde vinha".

Durante as observações das aulas de música em três escolas do município foi possível verificar o interesse das crianças pelo conteúdo musical e o desenvolvimento delas ao longo das semanas, mesmo quando o professor não tinha domínio do conteúdo apresentado.

\section{CONSIDERAÇÕES FINAIS}

É necessário um olhar especial tanto para a formação inicial quanto a formação continuada dos professores, para que a música seja de fato trabalhada como expressão artística e não apenas como um recurso na assimilação de conteúdos.

Como alternativa para cumprir a lei e efetivar o ensino de música na escola, sugerimos a contratação de profissionais licenciados em música nas redes de ensino, mesmo que essas contratações sejam realizadas gradativamente e com um número reduzido se comparado à necessidade, para que juntos, professores de música e professores dos anos iniciais do ensino fundamental, possam realizar um trabalho em parceria.

\section{REFERÊNCIAS}

ARAÚJO, R. Um estudo sobre os saberes que norteiam a prática pedagógica de professores de piano. Tese (Doutorado em Música)-PPG-Música, Universidade Federal do Rio Grande do Sul, Porto Alegre, 2005.

BELLOCHIO, C. Saberes docentes do educador musical: uma construção na prática profissional. In: Anais do XII Encontro Anual da ABEM. Florianópolis, SC, p.174-181, 2003.

BELLOCHIO, C; FURQUIM, A. A formação musical de professores unidocentes: um estudo em cursos de pedagogia. Revista da ABEM, 2010, v.24, p. 54-63, 2010.

GAULKE, T. Aprendizagem da docência em música: um estudo a partir de narrativas de professores de música da educação básica. 2013. 153 f. Dissertação (Mestrado em Música) - Instituto de Artes, Universidade Federal do Rio Grande do Sul, Porto Alegre.

GIL, A. C. Métodos e Técnicas de Pesquisa Social. 6a edição. São Paulo: 2008.

BRASIL, Lei no 11.769/08, de 18 de agosto de 2008. Altera a Lei n.. 9394/96, para dispor a obrigatoriedade do ensino de música na educação básica. Disponível em: <http://www.planalto.gov.br/ccivil_03/_Ato2007-2010/2008/Lei/L11769.htm>. Acesso em: 02 ago. 2013. 
PML - Prefeitura Municipal de Londrina. Secretaria Municipal de Educação de Londrina, 2014. Disponível em: <http://home.londrina.pr.gov.br> Acesso em: 20 jul. 2014.

PUERARI, M. Ensinar música na educação básica: um estudo de caso sobre o processo de escolarização da música na perspectiva de uma professora. 2-11. 112 f. Dissertação (Mestrado em Música) - Instituto de Artes, Universidade Federal do Rio Grande do Sul, Porto Alegre.

QUEIROZ, L. R. Escola, cultura, diversidade e educação musical: diálogos da contemporaneidade. In: InterMEio: Revista do Programa de Pós-Graduação em Educação. Campo Grande, MS, v. 19, n.37, p. 95-124, jan./jun. 2013.

TARDIF, M. Saberes docentes e formação profissional. 14 edição. Petrópolis, RJ: Vozes, 2012. 